\title{
Influence of Oxygen on Maltose Metabolism by Mucor rouxii
}

\author{
By A. FLORES-CARREÓN, EMMA REYES \\ AND J. RUÍZ-HERRERA \\ Departmento de Microbiología, Escuela Nacional de Ciencias Biologicas \\ Instituto Politecnico Nacional, Mexico I7, D.F., Mexico \\ (Accepted for publication I4 July 1969)
}

\begin{abstract}
SUMMARY
Mucor rouxii grew aerobically and anaerobically with glucose as carbon source; with maltose as carbon source the fungus grew only aerobically. Spores germinated in a glucose medium utilized anaerobically glucose but not maltose. Acetone powders or cell-free extracts obtained from glucosegrown mycelium, hydrolysed maltose aerobically and anaerobically. Maltose uptake and fermentation were inhibited by appropriate concentrations of $\mathrm{KCN}$, DNP and amytal. These results are interpreted to mean that a functional respiratory chain is required for maltose penetration into the cell.
\end{abstract}

\section{INTRODUCTION}

Some micro-organisms, mainly yeasts, are unable to utilize anaerobically certain disaccharides even though they can utilize them as sole sources of carbon in the presence of oxygen. No satisfactory explanation has been given of this phenomenon. Kluyver \& Custer (1940) suggested that the enzymes which hydrolysed disaccharides in these micro-organisms were reversibly inactivated in the absence of oxygen. More recently Bartnicki-García \& Nickerson ( $1962 b$ ), studying the nutritional control of morphogenesis of Mucor rouxii found that this fungus utilized disaccharides only under aerobic conditions. In further investigating this problem we selected maltose as a representative disaccharide. A preliminary report of our results has been published (Ruíz-Herrera \& Flores-Carreón, 1967).

\section{METHODS}

Organism. Mucor rouxii strains H I 2-SB and IM-80 were obtained from S. BartnickiGarcía (University of California, Riverside, U.S.A.).

Media. A complex yeast extract + peptone + glucose medium (YPG) and a defined medium described by Bartnicki-García \& Nickerson ( $1962 a$ ) were used.

Manometric techniques. To measure respiratory $\left(\mathrm{O}_{2}\right.$ uptake) and fermentative ( $\mathrm{CO}_{2}$ evolution) activities, standard manometric techniques were used (Umbreit, Burris \& Stauffer, I95I) under atmospheres of air and purified nitrogen, respectively. Spores obtained from mycelium grown in Roux bottles were resuspended in YPG or YPM (i.e. YPG medium containing maltose instead of glucose) media and germinated with shaking for 8 to $10 \mathrm{hr}$. Germination was followed microscopically. When nearly all spores had germinated, they were centrifuged down and washed twice with $0.05 \mathrm{M}-\mathrm{KH}_{2} \mathrm{PO}_{4}(\mathrm{pH} 4.5)$. Spores (equiv. Io to $20 \mathrm{mg}$. dry-weight) were placed in 
Warburg flasks. In the side arm $0.5 \mathrm{ml}$. of $0.01 \mathrm{M}$-maltose or $0.02 \mathrm{M}$-glucose was placed; final volume $3.2 \mathrm{ml}$, temperature $28^{\circ}$. When respiration was measured, $0.2 \mathrm{ml}$. of $50 \% \mathrm{KOH}$ was placed in the centre well. When fermentation was measured the system was evacuated three times and refilled with pure nitrogen.

Sugar uptake. Germinated spores (equiv. Io $\mathrm{mg}$. dry weight) were incubated with $2 \mathrm{mg}$. glucose or maltose in a final volume of $5.0 \mathrm{ml}$. At intervals, I ml. samples were removed, deproteinized and the residual total sugars and glucose were measured in the supernatant fluids.

Growth determination. Portions ( $15 \mathrm{ml}$.) of either defined or complex media were put in Erlenmeyer flasks or Thunberg tubes and inoculated with a washed spores suspension. Oxygen was replaced by $\mathrm{N}_{2}$ in the Thunberg tubes to create anaerobic conditions. Flasks and tubes were incubated with shaking at $28^{\circ}$ for $72 \mathrm{hr}$. The mycelium was recovered by filtration through Millipore filters, washed, dried and weighed.

Acetone powders. These were prepared from germinated spores by treatment with acetone at $-20^{\circ}$. The spores were rapidly filtered off, washed with cold acetone, the acetone evaporated under vacuum and the powder kept at $-20^{\circ}$ over $\mathrm{CaCl}_{2}$.

Sugars. Total sugars were measured by the anthrone procedure (Dimler, Shaeffer, Wise \& Rist, 1952). Glucose was determined with a commercial glucose-oxidase kit (Calbiochem) in samples previously deproteinized with $\mathrm{NaOH}$ and $\mathrm{ZnSO}_{4}$ (Somogyi, I939).

$\alpha$-glucosidase. This enzyme was measured as follows: maltose $(800 \mu \mathrm{g})$ and enzyme were mixed to a final volume of $5 \mathrm{ml}$. in $0.05 \mathrm{M}$-potassium phosphate buffer (pH 7.3). At intervals, samples were removed, deproteinized as above, and glucose was measured in the supernatant fluids. In some experiments, $3 \mathrm{ml}$. glucose-oxidase reagent were incubated together with $\alpha$-glucosidase and maltose in a volume of $5 \mathrm{ml}$. and the colour developed measured at intervals in a Klett colorimeter with blue filter.

\section{RESULTS}

Effect of oxygen on the growth of Mucor rouxii. We confirmed the report of Bartnicki-García \& Nickerson ( $1962 b$ ), who found that $M$. rouxii was unable to grow under anaerobic conditions with a disacchardide as carbon source. The results presented in Table I are evidence that $M$. rouxii grows anaerobically only with glucose as carbon source in complex and in defined media.

Table I. Effect of oxygen on the growth of Mucor rouxii

\begin{tabular}{|c|c|c|c|}
\hline Medium & Carbon source & $\begin{array}{c}\text { Aerobic* } \\
\text { Organism (mg } \\
\end{array}$ & 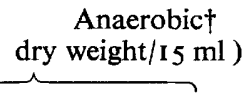 \\
\hline Defined & $\begin{array}{l}\text { glucose } \\
\text { maltose }\end{array}$ & $\begin{array}{r}18 \cdot 3 \\
7 \cdot 3\end{array}$ & $\begin{array}{l}2.35 \\
0.1\end{array}$ \\
\hline Complex & $\begin{array}{l}\text { glucose } \\
\text { maltose }\end{array}$ & $\begin{array}{l}16 \cdot 2 \\
36.7\end{array}$ & $\begin{array}{l}9 \cdot 7 \\
0.1\end{array}$ \\
\hline
\end{tabular}

Oxidation and fermentation of glucose and maltose by germinated spores of Mucor rouxii. Oxygen uptake was measured manometrically with glucose or maltose as substrate. The behaviour of spores germinated in presence of glucose or maltose 
(from here named G-spores and M-spores, respectively) was compared. The results obtained with strains IM-80 and H I2-SB showed that both sugars were oxidized irrespective of the carbon source used to germinate the spores, except that maltose oxidation by M-spores was more rapid than that of G-spores (Fig. I). These results suggested

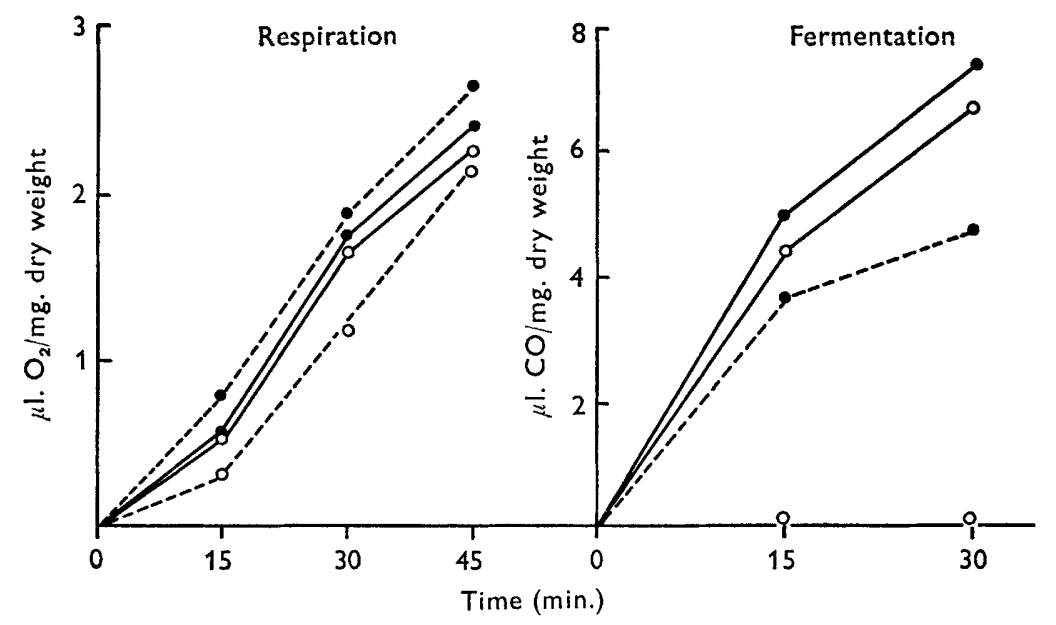

Fig. I. Oxidation and fermentation of sugars by Mucor rouxii. Samples equiv. Io mg. dry wt of spores of $M$. rouxii IM-80 were incubated in Warburg flasks with glucose or maltose. More data in the text. $O$, Glucose-grown spores; 0 , Maltose-grown spores. Continuous lines, glucose as substrate; dashed lines, maltose as substrate.

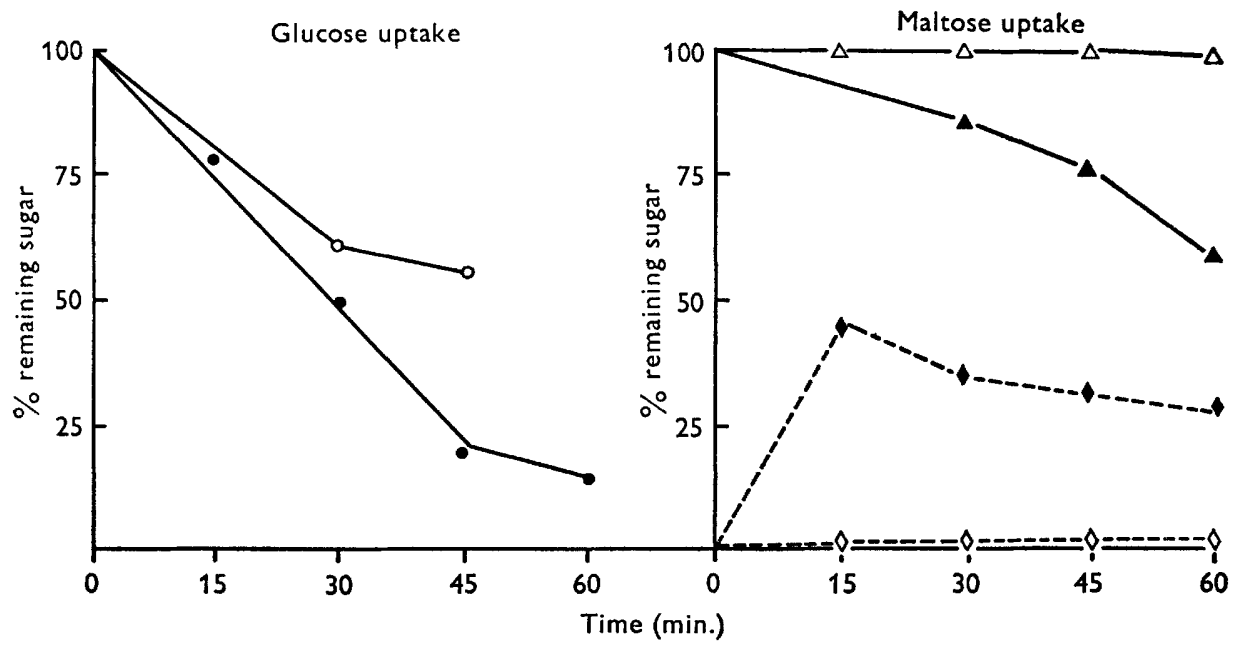

Fig. 2. Sugar uptake by Mucor rouxii under anaerobic conditions. In a final volume of $5.0 \mathrm{ml}$. of $0.05 \mathrm{M}-\mathrm{KH}_{2} \mathrm{PO}_{4}$ buffer ( $\mathrm{pH}_{4} .5$ ) germinated spores (equiv. $10 \mathrm{mg}$. dry weight) were incubated in Thunberg tubes in anaerobic conditions with $2 \mathrm{mg}$. maltose. At intervals, the tubes were opened, the mixtures deproteinized and total sugars and glucose were measured in the supernatant fluids. Open figures, glucose-germinated spores. Closed figures, maltosegerminated spores. $\bigcirc \mathbf{0}$, Glucose uptake; $\Delta \mathbf{\Lambda}$, maltose uptake; $\diamond \diamond$, glucose formed. 
that the enzyme systems involved in maltose metabolism were possibly constitutive in nature, and that oxygen was not necessary for its induction. Glucose was fermented by G-spores and by M-spores (Fig. I), but maltose was fermented only by M-spores. These results indicate that maltose was utilized by an oxygen-dependent system, and that through growth in maltose another system which did not require oxygen to metabolize maltose was synthesized.

Effect of oxygen on sugar uptake. Two mg. glucose or maltose were incubated with germinated spores (equiv. Io mg. dry weight) in a final volume of $5 \mathrm{ml}$. At intervals, samples were taken, deproteinized, and total sugars and glucose were measured in the supernatant fluids. The results obtained are shown in Fig. 2, 3. Glucose was consumed by either G- or M-spores, irrespective of the presence of oxygen. On the other hand, maltose was not consumed aerobically by $\mathrm{G}$-spores whereas $\mathrm{M}$-spores incubated with maltose consumed this disaccharide and accumulated glucose in the medium, which later disappeared slowly.

To circumvent cellular impermeability an acetone powder prepared from G-spores

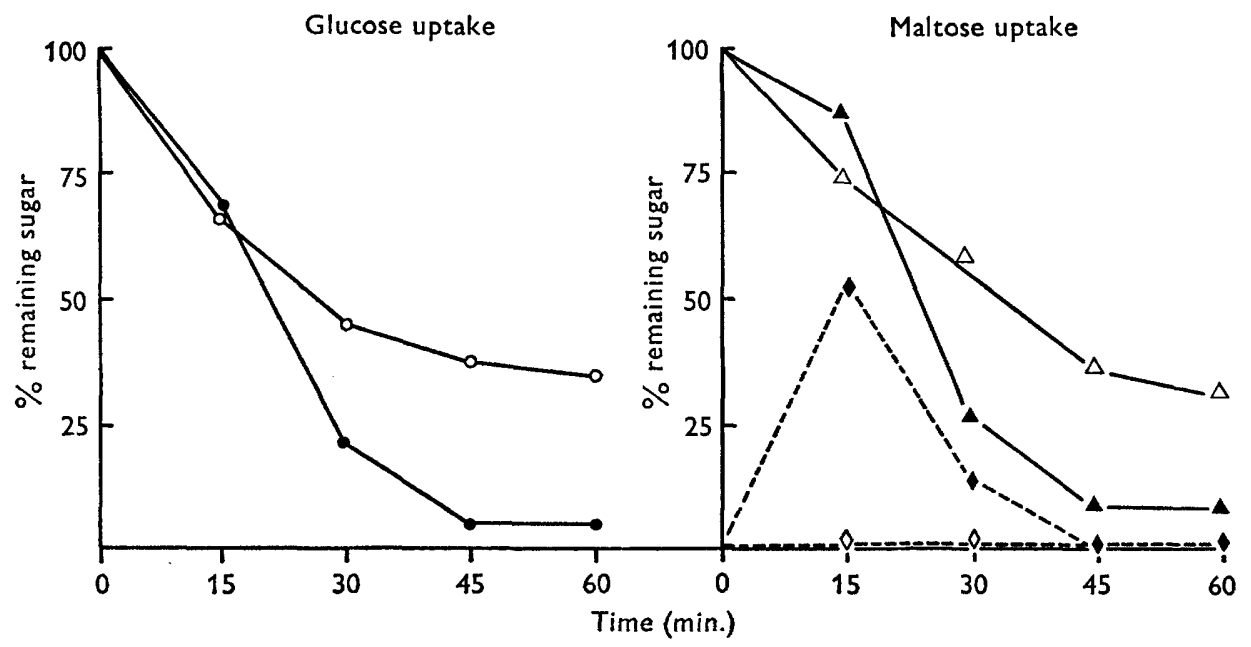

Fig. 3. Sugar uptake by Mucor rouxii under aerobic conditions. Conditions as described for Fig. 2, except that the mixtures were incubated in duplicate open flasks with shaking. Open figures, glucose-germinated spores; closed figures, maltose-germinated spores; $\bigcirc$, Glucose uptake; $\Delta \boldsymbol{\Delta}$, maltose uptake; $\diamond \diamond$, glucose formed.

(4 mg.) was incubated anaerobically in Thunberg tubes in the presence of maltose and glucose-oxidase reagent. No colour developed under these conditions. At the end of 9 min. of incubation the tube was opened and $0.5 \mathrm{~N}-\mathrm{NaOH}$ and $10 \%(\mathrm{w} / \mathrm{v}) \mathrm{ZnSO}_{4}$ were rapidly added to deproteinize the mixture. The material was centrifuged and fresh glucose-oxidase reagent added to the supernatant fluid. Immediate development of colour took place, indicating that maltose had been split to glucose during the anaerobic incubation. Blanks were simultaneously run to check the anaerobic conditions and whether $\mathrm{NaOH}+\mathrm{ZnSO}_{4}$ inactivated the enzyme. To test anaerobiosis, glucose was incubated with glucose-oxidase reagent; no colour was developed, indicating absence of free oxygen in the system. As second blank, organisms were incubated without maltose, and this added after deproteinization: no colour developed. The results of 
this experiment show that maltose hydrolysis did not require oxygen and that the organism possesses a constitutive $\alpha$-glucosidase. These results suggest that oxygen is probably necessary for maltose penetration into the cell. In further experiments mycelium grown either aerobically or anaerobically with glucose was broken with the help of a Ribi cell fractionator. In the two extracts, $\alpha$-glucosidase was detected in about equivalent amounts.

Effect of inhibitors. When G-spores were incubated aerobically in the presence of Io mM- or I mM-KCN, they fermented glucose actively. The corresponding controls where $\mathrm{CO}_{2}$ was trapped with $\mathrm{KOH}$ did not show any oxygen uptake, indicating that the terminal respiratory chain was completely blocked. With maltose instead of glucose, fermentation did not occur in the presence of Io mM-KCN (Fig. 4). This result may be interpreted as an indication that a functional respiratory chain is necessary for maltose uptake. This hypothesis was supported when it was found that Io $\mathrm{mM}$ - and I mM-KCN completely blocked maltose uptake, whereas glucose uptake was almost not affected.

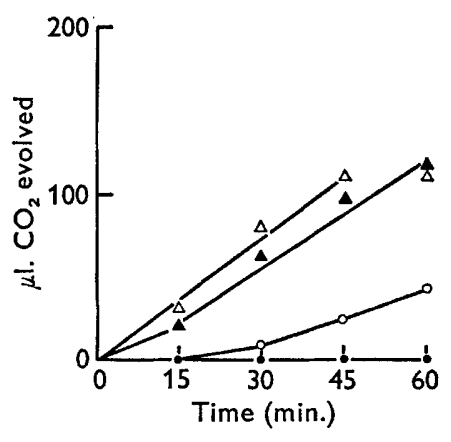

Fig. 4

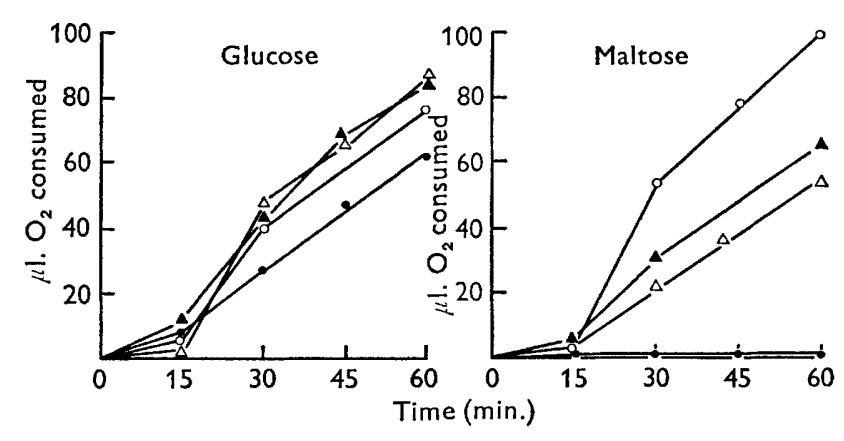

Fig. 5

Fig, 4. Effect of $\mathrm{KCN}$ on aerobic fermentation by Mucor rouxii. The protocol was as described for Fig. 1, except that only spores germinated in a glucose medium were used; $\mathrm{KCN}$ present at the indicated concentrations. No $\mathrm{KOH}$ was added to the centre well; gas phase air. $\Delta$, glucose + o.0I M-KCN; $\triangle$, glucose + I mM-KCN;, maltose +o.0 I M-KCN; $O$, maltose+ I mM-KCN.

Fig. 5. Effect of DNP and amytal on respiration by Mucor rouxii. Protocol as described for Fig. I, except that only glucose-germinated spores were used. $O$, no inhibitor added, $\triangle$, ०.oIM-DNP; O, O.OI M-amytal; $\triangle$, O.I M-DNP.

Other selective inhibitory substances tested were 0.I M DNP which inhibited maltose oxidation whereas it stimulated glucose oxidation, and amytal which blocked only maltose oxidation but not glucose oxidation when used at high concentrations (Fig. 5). At these concentrations both substances inhibited also maltose uptake.

\section{DISCUSSION}

Several micro-organisms have been shown to metabolize disaccharides by an initial oxidation with formation of either the respective bionic acid (Stodola \& Lockwood, 1947; Nishikuza \& Hayaishi, 1962) which may subsequently be hydrolysed as in Corynebacterium simplex (Bernaerts \& De Ley, 1954); or else oxidized to form a 3-keto-glucoside, i.e. oxidation of sucrose to 3-ketosucrose by Agrobacterium 
tumefasciens (Hayano \& Fukui, 1967). If such an oxidative pathway occurred during the metabolism of maltose by Mucor rouxii this might explain the oxygen requirement for maltose metabolism, but if this were true whole cells or cell-free extract kept anaerobically would be unable to metabolize maltose. If, on the other hand, maltose uptake required oxygen, cell-free extracts but not whole organisms should be able to hydrolyse maltose. Our data suggest that the oxygen-requiring system for maltose utilization by $M$. rouxii is probably related to sugar penetration across the permeability barrier of the cell. A certain concentration of $\alpha$-glucosidase is present in glucosegrown and in maltose-grown mycelium, and in organisms grown anaerobically or aerobically with glucose as carbon source. Apparently the substrate does not reach the intracellular enzyme under anaerobic conditions. When the permeability barrier is circumvented either by treatment with acetone or mechanical breakage of mycelium, the intracellular enzyme can hydrolyse exogenous maltose under anaerobic conditions. These results rule out the possibility that oxygen is necessary for maltose breakdown or for the inducible synthesis of $\alpha$-glucosidase. They are also against the hypothesis of Kluyver \& Custer (I940) that certain yeasts are unable to ferment some disaccharides because the enzymes involved in their hydrolysis are reversibly inactivated in anaerobic conditions.

It is difficult to conclude from the present data what the role of oxygen in maltose permeability is. A functional respiratory chain seems to be required for maltose entry since impairment of the electron transport by amytal or $\mathrm{KCN}$ or the presence of an uncoupling agent inhibited maltose uptake. $\mathrm{KCN}$ inhibits the uptake of amino acids in mouse brain slices (Neame, 196r) and citrate permeability in Aerobacter aerogenes (Villarreal \& Ruíz-Herrera, I969). Proline uptake by membrane preparations of Escherichia coli was shown to be an oxygen-dependent mechanism and was inhibited by DNP and amytal (Kaback \& Stadtman, I966). DNP was inhibitory of amino acid exchange diffusion and of active transport in rat kidney cortex (Schwartzman, Blair $\&$ Segal, 1967). These data indicate the existence of some linkage between oxidative metabolism and active transport. This linkage may be in the form of ATP which is required for cation transport in erythrocytes (Hoffman, 1962) and for the function of $\beta$-galactoside permease (Kepes, I964), or some other high energy compound formed only through aerobic metabolism. However, it must be stressed that the function of the maltose-transport system of Mucor rouxii is different from that of the maltose permease of $E$. coli (Wiesmeyer \& Cohn, 1960) and of Saccharomyces cerevisiae (Harris \& Thompson, 196I) both of which are active transport systems but function under either aerobic or anaerobic conditions (Flores-Carreón, I966).

\section{REFERENCES}

Bartnicki-García, S. \& Nickerson, W. J. (I962a). Induction of yeast-like development in Mucor by carbon dioxide. $J$ Bact. 84, 829 .

Bartnicki-García, S. \& Nickerson, W. J. (I962 b). Nutrition, growth and morphogenesis of Mucor rouxii. J. Bact. 84, 841.

Bernaerts, M. J. \& De Ley, J. (1954). The catabolism of lactose and lactobionate by Corynebacterium simplex. Antonie van Leeuwenhoek 23, 333.

Dimler, R. J., Shaeffer, W. C., Wise, C. S. \& Rist, C. E. (I952). Quantitative paper chromatography of D-glucose and its oligosaccharides. Analyt. Chem. 24, $141 \mathrm{I}$.

Flores-CARreón, A. (1966). The effect of oxygen upon the metabolism of disaccharides by microorganisms. Thesis Escuela Nacional de Ciencias Biológicas, I.P.N. México, D.F. (in Spanish). 
HARRIs, G. \& THOMPSON, C. C. (196I). The uptake of nutrients by yeast. III. The maltose permease of a brewing yeast. Biochim. biophys. Acta 52, 176.

Hayano, K. \& Fukui, S. (1967). Purification and properties of 3-Keto sucrose forming enzyme from the cells of Agrobacterium tumefasciens. J. biol. Chem. 242, 3665.

Hoffman, J.F. (1962). Cation transport and structure of the red cell plasma membrane. In Symposium on the Plasma Membrane. Ed. by A. P. Fishman. p. 120I. New York U.S.A.: American and New York Heart Association.

Kaback, H. R. \& Stadtman, E. R. (I966). Proline uptake by cytoplasmic membrane preparation of E. coli. Fedn Proc. Fedn Am. Socs exp. Biol. 25, 591.

KEPES, A. (1964). The place of permeases in cellular organization. In The Cellular Functions of Membrane Transport. Ed. by S. F. Hoffman p. I55. New Jersey, U.S.A.: Prentice-Hall Inc.

KlUYver, A. J. \& CUSTER, M. T. J. (1940). The suitability of disaccharides as respiration and assimilation substrates for yeast which do not ferment these sugars. Antonie van Leeuwenhoek 6, I 2 I.

NeAmE, D. K. (196I). Uptake of amino acids by mouse brain slices. J. Neurochem. 6, 358 .

NishikUZA, N. Y. \& HAYAISHI, O. (1962). Enzymic formation on lactobionic acid from lactose. $J$. biol. Chem. 237, 2721 .

Ruíz-Herrera, J. \& Flores-Carreón, A. (1967). Effect of oxygen on the utilization of maltose by Mucor rouxii. Bact. Proc. p. Io6.

Schwartzman, L., Blair, A. \& Segel, S. (1967). Effect of transport inhibitors on dibasic amino acid exchange in rat-Kidney. Biochim. biophys. Acta $135, \mathrm{I} 36$.

SomoGyi, M. (1939). A method for the preparation of blood filtrates for the determination of sugar. J. biol. Chem. 86, 655 .

Stodola, F. H. \& Lockwood, L. B. (I947). The oxidation of lactose and maltose to bionic acids by Pseudomonas. J. biol. Chem. 171, 213.

Umbreit, W. W., Burris, R. H. \& Stauffer, J. F. (I95I). Manometric Techniques and Tissue Metabolism. Minneapolis, Minn., U.S.A.: Burgess Publishing Co.

Villarreal, E. \& Ruíz-Herrera, J. (I969). Induction and properties of citrate transport system in Aerobacter aerogenes. J. Bact. 98, 552.

WiesMeYer, N. \& COHN, M. (1960). The characterization of the pathway of maltose utilization by Escherichia coli. III. Concentration mechanism. Biochim. biophys. Acta 39, 440. 